index •comunicación | no 12(1) 2022 | Páginas 99-120

E-ISSN: 2174-1859 | ISSN: 2444-3239 | Depósito Legal: M-19965-2015

Recibido el 23_08_2021 | Aceptado el 25_10_2021 | Publicado el 15_01_2022

\title{
REPENSANDO LA TECNOPOLÍTICA DESDE LOS PROCESOS ELECTORALES 2012 Y 2018 EN MÉXICO
}

\section{RE-THINKING TECHNOPOLITICS FROM 2012 AND 2018 MEXICAN PRESIDENTIAL ELECTIONS}

https://doi.org/10.33732/ixc/12/01Repens

\section{Isaac de Jesús Palazuelos Rojo Universidad Autónoma de Baja California isaac.palazuelos@uabc.edu.mx https://orcid.org/0000-0001-8150-9201}

\section{Alejandro Antonio Corvera Sánchez Universidad Autónoma Metropolitana Unidad Lerma a.corvera@correo.ler.uam.mx https://orcid.org/0000-0002-7421-5376}

\section{Irma Daniela Rentería Díaz Universidad Autónoma de Baja California daniela.renteria@uabc.edu.mx https://orcid.org/0000-0002-7423-0285}


Resumen: Este artículo propone el concepto de tecnopolítica como una vía para reflexionar sobre los cambios mediáticos tanto en expresiones de reivindicación, como en procesos de dominación social y de modelado de la opinión pública. Se realizó etnografía digital de corte longitudinal sobre los procesos electorales 2012 y 2018 en México. Se concluye que la tecnopolítica es un proceso de ensamblaje donde interactúan actores, con objetivos políticos diferenciados, que buscan transformar una historicidad dada o aspiran a conservar las estructuras políticas existentes, a través de movilizaciones, acciones en redes sociodigitales, creación de contenidos audiovisuales y otras apropiaciones tecnológicas.

Palabras clave: tecnopolítica; proceso electoral; redes sociodigitales.

Abstract: This article proposes the technopolitical concept as a way to reflect on media changes both in expressions of demand as in processes of social domination and the shaping of public opinion. Longitudinal digital ethnography was carried out on the 2012 and 2018 electoral processes in Mexico. It is concluded that technopolitics is an assembly process where actors interact, with differentiated political objectives, who seek to transform a given historicity or aspire to preserve existing political structures through mobilizations, actions in social media, media content production and other technological appropriations.

Keywords: Technopolitcs; Electoral Processes; Social Media. 


\section{Introducción}

Entre 2010 y 2015 ocurrieron diversos fenómenos políticos que involucraron una ciudadanía participativa cuyo activismo se caracterizó por el uso de redes sociodigitales. El Yo Soy 132, movimiento red que irrumpió la narrativa impuesta por los medios hegemónicos durante el proceso electoral federal de 2012 en México (Ramírez, 2020; Estrada, 2014; Morales, 2014 y Valenzuela, 2015); el Occupy Wall Street, campamento instaurado con una forma novedosa de contención política: estructura descentralizada y rizomática, denunciando la desigualdad económica en Estados Unidos de América (Flores-Márquez, 2020; Benson, 2015); el 15M, movimiento inédito de organización en red y características únicas de manifestación que terminaron influyendo en las campañas electorales de España en 2011 (Calvo, Gómez-Pastrana, y Mena, 2011); el Pase Livre movimiento de jóvenes a través del uso de redes sociodigitales y teléfonos móviles para coordinar eventos de protesta exigiendo la mejora del transporte y otros servicios públicos en Brasil (Spiro y MonroyHernández, 2016).

Tales eventualidades son referentes empíricos de una manera nueva de hacer política. Para autores como Reguillo (2015), Toret, Calleja-López, Marín, Aragón, Aguilera, y Lumbreras, (2013) y Valenzuela (2015), esta novedosa forma de hacer política tiene como base una suma de condiciones: tiende a ser transitoria, se organiza en red y posee la cualidad de irrumpir narrativas verticales impuestas por la hegemonía de los medios tradicionales de comunicación. Son expresiones políticas carentes de forma, de límites, descentralizadas y generalmente apartidistas.

Esta narrativa acerca de la apropiación de redes sociodigitales y su consecuente transformación en la forma de hacer política, desde la sociedad civil organizada, forma parte de un panorama alentador para las reivindicaciones sociales en el mundo. El argumento común es la noción de insurrección (Reguillo, 2015; 2017), así como el surgimiento de una nueva esfera pública en la que las personas, particularmente las juventudes, construyen ciudadanía a través de la capacidad de discutir y deliberar sobre el mundo social, desde espacios autónomos e indeterminados por las instituciones gubernamentales o por el mercado (Treré, 2015).

En este sentido, los analistas del proceso electoral mexicano en 2012 se centraron en visibilizar que la transición de gobierno tuvo lugar en un contexto de fuertes demandas y expectativas ciudadanas que se hicieron notar a través de la movilización juvenil del \#YoSoy132. Aunque ésta perdió solidez hasta su extinción, como todo movimiento social generalmente tiende a hacerlo, los estudios insistieron en señalar que tales movilizaciones lograron cuestio- 
nar la legitimidad del proceso electoral, incitando al diálogo entre el mecanismo institucional democrático y distintos sectores ciudadanos, destacando a los jóvenes. También se subraya que el \#YoSoy132 instauró en México el uso de la tecnopolítica, a través de las redes sociodigitales, como un mecanismo de reivindicación (Reguillo, 2015; Valle, 2015; Morales, 2014 y Estrada, 2014).

Estas interpretaciones constituyen un importante punto de partida al describir la participación política conectada en red y en devenir insurrecto. No obstante, son reflexiones inacabadas, pues han dejado de lado el uso de redes como herramienta de reproducción y de conservación de estructuras políticas; por tanto, aún nos falta mucho por descubrir en torno a las relaciones de poder entre una diversidad de actores que interactúan en estas ecologías mediáticas. Desde el 2016, diversos estudios señalan esta parte antagónica, surgieron conceptos como el de dataficación (Milan y Treré, 2017) usado para referir nuevas formas de control y desigualdad social a través del capitalismo de datos. Asimismo, destacan fenómenos como el de las fake news y el uso de bots como estrategia para modelar la opinión pública (Shao, Luca, Varol, Flammini y Menczer, 2017).

Por nuestra parte, subrayamos el retorno de nacionalismos que se vislumbran en episodios puntuales y el papel que tienen las encuestas, promovidas en redes sociodigitales en relación con decisiones populares, como el triunfo electoral de Donald Trump, la salida del Reino Unido de la Unión Europea mediante el voto del Brexit y la negativa al Plebiscito sobre los acuerdos de Paz en Colombia (Velásquez, 2016 y García y Chicaíza, 2018). En paralelo a estos acontecimientos, en 2018 Facebook se enfrentó a una de sus mayores crisis de credibilidad y confianza ante una fuga masiva de datos de usuarios. Diversas investigaciones desde la academia y el periodismo (Brown, 2020; Rossenberg, Confessore y Cadwalladr, 2018; Cadwalladr y Graham-Harrison, 2018), revelaron que Cambridge Analytica robó la información de más cincuenta millones de perfiles de usuarios, con la intención de diseñar estrategias estratificadas de campaña electoral durante las elecciones de 2016 en Estados Unidos. Lo anterior, demuestra la posibilidad del uso de redes sociodigitales para fines políticos no reivindicativos.

Observamos en los estudios sobre la apropiación política de las redes un binarismo: por una parte, está el planteamiento que sostiene la existencia de un empoderamiento ciudadano con diversas capacidades de transgresión social, provistas por unos usos reivindicativos de las redes sociodigitales (Castells, 2012; Toret et al., 2013 y Reguillo, 2017); por otra parte, destaca un revestimiento del poder comunicacional que se refuerza con la emergencia de nuevos espacios de control instrumental, determinados principalmente por el 
mercado y, en menor medida, por instituciones gubernamentales. Es decir, un dispositivo panóptico digital (Ventura, 2018) y unos enmarcados mediáticos que imponen la orientación política de los votantes (Castells, 2009).

En el caso de México dicho binarismo tuvo lugar en los procesos electorales del 2012 y 2018. En la primera fecha, apreciamos que las redes se emplearon como estrategia electoral del Partido Revolucionario Institucional (PRI), centrándose en la mediatización del entonces candidato a la presidencia Enrique Peña Nieto, cuya campaña recurrió a las estructuras narrativas de las telenovelas mexicanas, respaldado por las empresas de comunicación más influyentes del país, mediante la elaboración de spots difundidos en YouTube (Ángeles, 2020).

Mientras que en la segunda fecha, CNN (11 de abril de 2018) reveló que el director ejecutivo de Cambridge Analytica, Alexander Nix, sostuvo reuniones en México con partidos políticos nacionales y miembros del gobierno federal. Simultáneamente, el presidente del Instituto Nacional Electoral, Lorenzo Córdova, celebró un acuerdo con Facebook (Rivera-Velázquez, 2018), el cual favoreció la acumulación de datos por parte de la empresa, pues establece que el Instituto brindaría información en tiempo real sobre el acontecer y los resultados preliminares de la jornada electoral. Según relata Zavala (2018), el convenio se publicitó como un mecanismo para combatir la difusión de fake news aunque el documento detalla poco al respecto. Para este momento las redes sociodigitales figuraban como un factor de peso mediático en los procesos electorales a nivel internacional y, a pesar de que en 2014 en México se realizó una reforma a la Ley Electoral, estas plataformas todavía permanecen carentes de toda regulación.

Los señalamientos anteriores muestran que, desde los primeros acontecimientos vinculados con la apropiación política de las redes en México, estas se han usado no solo como un medio de expresión reivindicativa, sino también como una herramienta para la reproducción y conservación de las estructuras de poder. Por tanto, partimos de la hipótesis de que en los procesos electorales federales de México en 2012 y 2018, las redes sociodigitales desempeñaron un papel importante en la experiencia política en un contexto bifurcado entre el empoderamiento comunicativo y el modelado de la opinión pública. El objetivo de nuestra investigación es analizar las diversas formas de apropiación tecnológica así como sus capacidades y estrategias narrativas, a fin de determinar los fines políticos que persiguen los usuarios desde la sociedad civil y desde los partidos políticos. 


\section{Marco teórico}

\subsection{Repensar la tecnopolítica desde la complejidad}

Toret et al., (2013) acuñan el concepto de tecnopolítica para referirse a la capacidad masiva de autoorganizarse, a través de la producción de estados anímicos empoderados, en acciones colectivas mediadas por el uso de redes sociodigitales. Para comprender el concepto, es necesario recurrir a otros referentes que lo van definiendo, de acuerdo con esta propuesta el sistema red, es entendido como un tejido de nodos conectados en forma de red de estructura abierta y policéntrica. Se trata de una reconceptualización de las movilizaciones sociales, en la que la acción colectiva no es determinada por un centro de mando único, sino que es una estructura compleja en la que convergen deseos similares.

El referente de Multitud conectada explica la manera en que distintas personas pueden establecer una conexión digital con base en un objetivo común, en tiempo, espacio, lenguaje, emociones y comportamiento. Los acontecimientos aumentados son formas de intensificación de sucesos que son contenidos en las redes sociodigitales, desde las cuales los sentimientos se robustecen y se multiplican a través del contagio tecnológicamente estructurado, mismo que produce una viralidad e impulso de participación y solidaridad.

Siguiendo a Toret y Pérez (2012), los internautas que participan de la reivindicación tecnopolítica, devienen cíborg a través de una apropiación tecnológica en la que su corporalidad se esparce a través de redes digitales, en virtud de las cuales se logran formas organizativas en función del cumplimiento de objetivos políticos conjuntos. Estas formas de organización son definidas por los autores como inteligencias colectivas, que se componen de distintos cuerpos conectados y contagiados entre sí. Compuestos biotecnológicos que habitan redes múltiples. Desde esta visión, los cíborgs se entienden como cuerpos extendidos a la multiplicidad de la red digital de manera simbiótica. Son sujetos que se descorporizan al distribuir sus ideas y al vincularse a través de la red, dando lugar a formaciones de inteligencias colectivas, que actúan mediante la tecnopolítica para potencializar la acción ciudadana vinculada a una autoorganización, a partir del uso de redes sociodigitales.

El concepto cíborg tiene sus raíces en Haraway (1995), quien lo definió como un híbrido entre máquina y organismo que es producto de la cultura y la realidad social, pero a la vez de una forma de ficción. De acuerdo con la autora, el cíborg ocupa una ironía entre la seriedad y el humor, que definen una estrategia política de seres que cohabitan en un mundo natural y artificial. En palabras de la autora: «somos quimeras, híbridos teorizados y fabricados de máquina y organismo; en una palabra, somos ciborgs. Éste es nuestra ontología, 
nos otorga nuestra política. Es una imagen condensada de imaginación y realidad material, centros ambos que, unidos encuentran cualquier posibilidad de transformación histórica». (Haraway, 1995: 254).

El resultado de los cíborgs es la reinvención, tales transformaciones pueden estar situadas en diferentes contextos y favorecer a distintos propósitos de reinvención política, que no necesariamente se constriñen a fuerzas reivindicativas. El contexto de análisis usado por Toret y sus colaboradores se enfoca en el $15 \mathrm{M}$ español. Si las nociones abordadas se constriñen a procesos de insurrección, sus alcances explicativos no se explotan al máximo. La tecnopolítica no puede reducirse a un plano de insurrección, sino que más bien, está vinculada con una necesidad comunicativa extrapolada a una ecología mediática. Más allá de un vínculo exclusivo con movimientos de reivindicación social, se aplica también a otras expresiones políticas que pueden escapar a esta noción y figurar en un plano contrario, es decir, la dominación por la determinación del uso de dispositivos tecnológicos al servicio de un control social, que bien puede estar asociado a nuevas formas de vigilancia panóptica (Ventura, 2018).

Si el concepto se reduce a expresiones de insurrección corre el riesgo de provocar un paralelismo entre las nociones de autoorganización y búsqueda de autonomía política. Para Luhmann (1991) la autoorganización refiere una metáfora que compara la formación, reproducción y transformación de los grupos sociales, con la circularidad reproductiva y metabólica de los seres vivos, la organización de lo vivo que Maturana y Varela (1994) definieron como la autopoiesis. Luhman (1991) acuñó el concepto para explicar que los sistemas sociales se reproducen mediante un mecanismo autorreferencial y se configuran de componentes producidos por los mismos sistemas o sus entornos que están, a su vez, compuestos por otros sistemas.

La tecnopolítica pensada únicamente desde reivindicaciones sociales corre el riesgo de confundir la autopoiesis con la insurrección o la búsqueda de autonomía política; como si la autoorganización implicara, por sí misma, un desprendimiento de las instituciones o de las estructuras sociales; como si las instituciones políticas y las estructuras sociales fueran una fuerza rígida carente de esta autorreferencialidad a la que alude Luhman (1991). Podemos ser presas de un reduccionismo que niega la complejidad y se constriñe a visibilizar insurrecciones ciudadanas frente a formas de dominación del sistema político. De acuerdo con Escobar y Osterweil (2009), al abordar este binarismo es necesario considerar que se trata de «entidades discretas independientes», que, aunque «requieren una cierta polimorfía periférica 
[...] nunca puede haber una oposición o resistencia puras» (Escobar y Osterweil, 2009: 141, 145-146).

La particularidad de las movilizaciones políticas contemporáneas nos obliga a retomar planteamientos imparciales como el de Tilly (2010), quien señala que incluso las reivindicaciones más novedosas que recurren al uso de redes sociodigitales pueden asumir facetas de posición, en las que se vinculan sistemas y actores políticos que se ven favorecidos con sus repertorios de acción. Pensar que toda reivindicación es una lucha entre dos fuerzas, es negar que existen complejas asociaciones de ensamblajes entre los polos más visibles en disputa. Debido a la naturaleza compleja de las redes sociodigitales, la tecnopolítica como mecanismo de autoorganización no puede reducirse a una sola dimensión de este binarismo, demanda el rastreo de asociaciones y ensamblajes complejos entre polos aparentemente distantes.

Treré y Barranquero (2018) rastrean los diferentes usos de la tecnopolítica dentro de la academia y el activismo. Plantean la necesidad de realizar diálogos entre los diferentes contextos en los que su uso ha tenido lugar, para consolidar definiciones más amplias a partir del intercambio de experiencias afines o diferenciadas. Señalan que una definición precisa permite rechazar determinismos tecnológicos, revalorizando el papel de los contextos políticos, sociales y culturales; tomando distancia de otros determinismos sociales que niegan la importancia de la tecnología.

Asimismo, refieren la idea de que la implementación tecnológica es una formación nodal compuesta por tensiones y controversias. Explican que la apropiación política de la tecnología tiende a generar nuevas formas de poder, pero también nuevas maneras de expresar y ejercer la agencia. En ese sentido, la tecnología no puede ser entendida únicamente como un instrumento empleado en ámbitos políticos sino como un elemento que tiene la fuerza necesaria para transformar la política. La tecnopolítica puede entenderse como el estudio de dichas transformaciones, particularmente, a partir de las redefiniciones del tiempo y el espacio que se dan con la implementación tecnológica en la persecución de objetivos políticos (Treré y Barranquero, 2018).

\subsection{Enmarcados mediáticos}

En su análisis sobre el papel del poder y la comunicación en los procesos electorales, Castells (2009) advierte que el enmarcado mediático dibuja un perímetro en la interpretación de los ciudadanos con respecto a los candidatos, los partidos y las propuestas que éstos presentan como parte de sus campañas políticas. Este perímetro interpretativo se introduce en las mentes de los electores a través de la distribución de materiales audiovisuales. En tal proceso se imponen unidades mínimas de sentido, de manera que, al momento de ejercer 
su voto, los ciudadanos tienden a tomar una decisión con base en fórmulas cortas y memorizables, en lugar de reflexiones complejas en torno a las propuestas y su efectividad en la resolución de problemáticas sociales. Una canción de campaña, una combinación particular de colores e imágenes puede llegar a tener mucho más peso que una propuesta de política pública planteada por los candidatos durante su campaña.

Castells (2009) plantea que hay una continuidad del ejercicio de poder y la fuerza de consumo que ejercen las empresas de los medios tradicionales en los espacios digitales. Es decir, la información que más se consume en las redes sociodigitales es aquella producida por las grandes cadenas de noticias que han tenido presencia en la escena pública desde antes de la aparición de estas plataformas. Autores como Benkler, Faris, Roberts y Bourassa (2018) discuten las formas en que los problemas de desinformación, así como la baja calidad de la información, se enraízan en cuestiones socio políticas, descartando que sea por determinismos tecnológicos. Coinciden con Castells (2009) al señalar que la fuerza de las empresas hegemónicas de medios ejerce una continuidad en las redes sociodigitales y añaden que, derivado de intereses políticos, son estas mismas empresas las principales promotoras tanto de noticias falsas como de información de baja calidad.

Tanto la distribución de noticias falsas como la formulación de información de baja calidad juegan un papel importante en la interacción digital de los internautas; sin embargo, no son un producto directo de la inteligencia artificial o de la presencia de bots, sino que ambas deben entenderse en un contexto más amplio que incluye procesos políticos y sociales, que tienen un gran peso en el diseño de los enmarcados mediáticos, debido a un trasfondo de intereses y especulaciones por parte de grupos que ejercen el poder.

Los enmarcados mediáticos situados en contextos de especulación política producen dificultades comunicativas entre los internautas. De acuerdo con las reflexiones elaboradas por Berardi (2018), el paradigma de la comunicación actual a través de la conectividad en redes sociodigitales, produce relaciones en las que interactúan diferentes formatos, los cuales limitan las interpretaciones de los interlocutores y reducen los signos a significados unidimensionales. De manera que, cuando dos personas poseen diferentes formatos de interpretación, u comunicación es casi imposible. Frente a esta incapacidad de interpretar a la otra persona, se produce lo que el autor denomina epidemia de descortesía, la cual puede ser a su vez un generador de violencia por falta de entendimiento. 


\section{Metodología}

Nuestra investigación es de tipo cualitativo de carácter descriptivo, cuyo abordaje se realizó desde el método de la etnografía digital a fin de comprender la forma cómo los sujetos significan y actúan en su realidad (Pink, Horst, Postill, Hjorth, Lewis y Tacchi, 2016). Empleamos la observación participante en redes sociodigitales, para ello, hicimos un seguimiento a las páginas de Facebook, Twitter y YouTube de los tres principales frentes políticos que compitieron por la presidencia de la república en los dos periodos electorales analizados. En el 2012 realizamos un exhaustivo seguimiento de tres movimientos políticos: el Partido Acción Nacional, las coaliciones Compromiso por México y Movimiento Progresista, durante el periodo del 1 de enero al 30 de agosto.

Mientras, en el 2018 enfocamos la atención en el periodo del 1 de enero al 08 de julio, siguiendo las tres integraciones partidistas más importantes de la contienda electoral, en este caso fueron las coaliciones Por México al Frente, Juntos Haremos Historia y Todos por México. Con base en dicha distribución metodológica, perseguimos el objetivo de entender cómo se estaban configurando los usos de redes sociodigitales en torno a las campañas electorales, desde la sociedad civil y desde los partidos políticos.

El análisis de la información lo realizamos a partir de una muestra de 213 materiales audiovisuales recolectados en la etnografía digital en el proceso electoral del 2012, y 1241 recopilados en 2018, respectivamente. Agrupamos dicha muestra en memes, infografías, pendones, composiciones, videos en vivo y videos editados. Asimismo, categorizamos estos materiales en función de sus recursos narrativos y estrategias comunicativas, tal como lo mostramos en la siguiente tabla:

Tabla 1. Tipos de materiales audiovisuales analizados en campo

\begin{tabular}{|c|c|c|c|c|}
\hline Material & $\begin{array}{c}\text { Muestra } \\
2012\end{array}$ & $\begin{array}{c}\text { Muestra } \\
2018\end{array}$ & Recurso narrativo & $\begin{array}{c}\text { Estrategia } \\
\text { comunicativa }\end{array}$ \\
\hline Memes & 113 & 298 & $\begin{array}{l}\text { Son proyecciones visua- } \\
\text { les minimalistas y suge- } \\
\text { rentes, elaboradas ma- } \\
\text { yormente a partir de una } \\
\text { a cuatro secciones, aun- } \\
\text { que este número puede } \\
\text { variar. Al combinar fra- } \\
\text { ses con imágenes for- } \\
\text { man estructuras narrati- } \\
\text { vas que articulan el } \\
\text { humor, la sátira y la } \\
\text { crítica. La creatividad del } \\
\text { meme incrementa con la }\end{array}$ & $\begin{array}{l}\text { Este tipo de mate- } \\
\text { riales tiene una } \\
\text { tendencia hacia el } \\
\text { humor y la sátira. } \\
\text { Generalmente } \\
\text { recurren a ele- } \\
\text { mentos simbólicos } \\
\text { de la cultura occi- } \\
\text { dental, personajes } \\
\text { o escenas de } \\
\text { películas, series, } \\
\text { caricaturas y } \\
\text { programas de }\end{array}$ \\
\hline
\end{tabular}




\begin{tabular}{|c|c|c|c|c|}
\hline & & & $\begin{array}{l}\text { disminución de los ele- } \\
\text { mentos que lo compo- } \\
\text { nen y la forma en que } \\
\text { este minimalismo expre- } \\
\text { sivo puede conectar con } \\
\text { el imaginario colectivo. }\end{array}$ & $\begin{array}{l}\text { televisión, inte- } \\
\text { grantes de grupos } \\
\text { musicales, entre } \\
\text { otros elementos } \\
\text { mediáticos, tal } \\
\text { característica los } \\
\text { incluye en el gru- } \\
\text { po de remakes, ya } \\
\text { que trasladan un } \\
\text { contenido audiovi- } \\
\text { sual previo a otro } \\
\text { contexto reelabo- } \\
\text { rando su signifi- } \\
\text { cado. }\end{array}$ \\
\hline Infografías & 12 & 63 & $\begin{array}{l}\text { Presentan un contenido } \\
\text { textual amplio, desarro- } \\
\text { llado y explícito que se } \\
\text { sintetiza mediante el uso } \\
\text { de oraciones, cifras e } \\
\text { imágenes gráficas. A } \\
\text { diferencia de los memes, } \\
\text { las infografías requieren } \\
\text { de habilidades de diseño } \\
\text { relativamente altas. }\end{array}$ & $\begin{array}{l}\text { Cumplen la fun- } \\
\text { ción de sintetizar } \\
\text { datos e informa- } \\
\text { ciones complejas } \\
\text { que se derivan de } \\
\text { situaciones, dis- } \\
\text { cursos, notas de } \\
\text { periódico, colum- } \\
\text { nas de opinión, } \\
\text { artículos de revis- } \\
\text { tas e incluso li- } \\
\text { bros. General- } \\
\text { mente recurren a } \\
\text { fuentes de infor- } \\
\text { mación legítima, } \\
\text { consultable o } \\
\text { contrastable. }\end{array}$ \\
\hline Pendones & 45 & 362 & $\begin{array}{l}\text { Pueden combinar textos } \\
\text { con imágenes o em- } \\
\text { plearlas por separado. } \\
\text { Por lo general usan una } \\
\text { sola imagen acompaña- } \\
\text { da también de una sola } \\
\text { palabra o frase muy } \\
\text { breve, aunque en algu- } \\
\text { nos casos presentan } \\
\text { mezclas más desarrolla- } \\
\text { das. }\end{array}$ & $\begin{array}{l}\text { Tienen la función } \\
\text { de promocionar a } \\
\text { los candidatos, } \\
\text { partidos y coali- } \\
\text { ciones, mediante } \\
\text { la seducción de la } \\
\text { imagen, apelando } \\
\text { a diseños estéti- } \\
\text { camente agrada- } \\
\text { bles y frases iden- } \\
\text { tificables. Tienen } \\
\text { un vínculo directo } \\
\text { con estrategias de } \\
\text { mercado, en un } \\
\text { sentido trasladan } \\
\text { a las redes socio- } \\
\text { digitales las viejas } \\
\text { formas visuales } \\
\text { de hacer campaña } \\
\text { electoral en calle. }\end{array}$ \\
\hline
\end{tabular}




\begin{tabular}{|c|c|c|c|c|}
\hline Composiciones & 15 & 185 & $\begin{array}{l}\text { Se elaboran a partir de } \\
\text { correlacionar fragmentos } \\
\text { muy recortados de reali- } \\
\text { dades, a través de los } \\
\text { cuales se establecen } \\
\text { especulaciones y deduc- } \\
\text { ciones fundadas en uni- } \\
\text { dades mínimas de senti- } \\
\text { do. }\end{array}$ & $\begin{array}{l}\text { Composiciones } \\
\text { entre imágenes y } \\
\text { textos, usadas } \\
\text { para expresar } \\
\text { interpretaciones } \\
\text { en torno a la } \\
\text { realidad política y } \\
\text { social. Pueden } \\
\text { parecerse mucho } \\
\text { a un meme, pero } \\
\text { su función no es } \\
\text { humorística ni } \\
\text { satírica, sino que } \\
\text { se emplean para } \\
\text { denostar o acusar } \\
\text { situaciones y } \\
\text { conductas vincu- } \\
\text { ladas con los } \\
\text { partidos o a los } \\
\text { actores políticos. } \\
\text { Muchas de las } \\
\text { fake news se } \\
\text { distribuyen a } \\
\text { través de este } \\
\text { formato. }\end{array}$ \\
\hline $\begin{array}{l}\text { Videos } \\
\text { en vivo }\end{array}$ & 0 & 231 & $\begin{array}{l}\text { Tienen funciones como } \\
\text { la de denunciar y difun- } \\
\text { dir, ya sea situaciones o } \\
\text { eventualidades en tiem- } \\
\text { po real. En ocasiones se } \\
\text { acoplan con viejos for- } \\
\text { matos televisivos; algu- } \\
\text { nos de estos forman } \\
\text { parte de noticieros que } \\
\text { complementan su difu- } \\
\text { sión a través de strea- } \\
\text { ming, pero también } \\
\text { recurren a él usuarios } \\
\text { independientes, que se } \\
\text { valen de estas herra- } \\
\text { mientas para difundir } \\
\text { sus contenidos o expe- } \\
\text { riencias. }\end{array}$ & $\begin{array}{l}\text { Recurren al su- } \\
\text { puesto de que la } \\
\text { eventualidad } \\
\text { transmitida posee } \\
\text { suficiente fuerza } \\
\text { narrativa por sí } \\
\text { misma. Su estra- } \\
\text { tegia comunicati- } \\
\text { va se reduce a la } \\
\text { selección de en- } \\
\text { cuadres y de } \\
\text { espacios de difu- } \\
\text { sión. Pueden } \\
\text { también tener la } \\
\text { intención de ex-- } \\
\text { presar opiniones } \\
\text { individuales o } \\
\text { grupales, median- } \\
\text { te formatos de } \\
\text { monólogos, entre- } \\
\text { vistas y foros de } \\
\text { diálogo. }\end{array}$ \\
\hline & & & $\begin{array}{l}\text { Sus formatos varían } \\
\text { según la capacidad téc- } \\
\text { nica de quien los hace, } \\
\text { puede tratarse de pro- } \\
\text { ducciones elaboradas en }\end{array}$ & $\begin{array}{l}\text { Generalmente se } \\
\text { acoplan con for- } \\
\text { matos de remake } \\
\text { al reutilizar frag- } \\
\text { mentos de imáge- }\end{array}$ \\
\hline
\end{tabular}




\begin{tabular}{|l|l|l|l|}
\hline \multirow{1}{*}{$\begin{array}{l}\text { Videos } \\
\text { editados }\end{array} \quad 102$} & $\begin{array}{l}\text { agencias de community } \\
\text { manager, pero también } \\
\text { en otros contextos inde- } \\
\text { pendientes, desde donde } \\
\text { se emplean computado- } \\
\text { ras para la edición de } \\
\text { videos. }\end{array}$ & $\begin{array}{l}\text { nes y videos usa- } \\
\text { dos en otras pro- } \\
\text { ducciones, o al } \\
\text { reelaborar pro- } \\
\text { ducciones cam- } \\
\text { biando el conteni- } \\
\text { do de los audios o } \\
\text { el sentido de las } \\
\text { situaciones y de } \\
\text { los personajes. } \\
\text { También hay } \\
\text { producciones } \\
\text { originales, que } \\
\text { pueden incluir } \\
\text { animaciones, que } \\
\text { están orientadas a } \\
\text { distintos fines } \\
\text { como informar, } \\
\text { promocionar, } \\
\text { denostar, acusar, } \\
\text { denunciar o difun- } \\
\text { dir información en } \\
\text { relación con los } \\
\text { candidatos. }\end{array}$ \\
\hline
\end{tabular}

Fuente: elaboración propia.

Derivado de la categorización anterior realizamos conjunciones discursivas, explicando los usos de las redes sociodigitales en los dos periodos electorales analizados. Lo cual nos permite construir inferencias teóricas en torno al concepto de tecnopolítica, así como sus alcances explicativos en contextos poco explorados de la apropiación de los medios sociales en diversas expresiones políticas, particularmente desde la estructura narrativa de las campañas de candidatos a puestos de elección popular, así como la respectiva interpretación y respuesta por parte de los votantes.

\section{Resultados}

En nuestro trabajo de campo sobre los procesos electorales de 2012 y 2018 en México, apreciamos que la agenda mediática mayormente es dictada de arriba hacia abajo, con la diferencia de que se construye de maneras complejas, recibiendo críticas y reinterpretaciones que se devuelven en forma de materiales audiovisuales que también pueden ser consumidos por las audiencias. Los usuarios de redes sociodigitales reciben paquetes de información ya sea en su versión hegemónica, es decir, producidos por los equipos de campaña electoral, o ya sea a través de contenidos re-representados, sintetizados y satirizados por remakes en forma de memes o videos editados. En ocasiones puede ser este el primer encuentro o incluso el único, entre el usuario y la información. 
A partir del análisis de la muestra detectamos que el prosumo no todo el tiempo está en función de una autorrepresentación vernácula, sino que puede expresar y, según hemos observado, mayormente es así, formas de rerepresentación que rebotan los enmarcados mediáticos. En otras palabras, no todo el tiempo se trata de la creación de contenidos originales e inéditos, sino que parten de las representaciones políticas que hacen los equipos de campaña a través de medios hegemónicos. Es por este motivo que la categoría de remake suele tener mayor presencia, reforzando o contradiciendo tales recursos narrativos, mediante negociaciones que se hacen entre distintos creadores audiovisuales hegemónicos y no hegemónicos, cuyos contenidos circulan en la ecología mediática.

Encontramos que existe una continuidad del enmarcado mediático, en la autocomunicación multitudinaria que emana de los prosumidores y los remakes, de aquellas audiencias y creadores que no producen para las grandes firmas de noticias. Ya que los diferentes niveles de autonomía de los contenidos elaborados por usuarios de redes sociodigitales, son producto de la asociación de ensamblajes complejos entre los recursos narrativos y las estrategias comunicativas usadas desde las campañas.

Identificamos que en el proceso electoral del 2012 la tecnopolítica se hizo presente a través del movimiento juvenil \#YoSoy132 que se reivindicó de manera descentralizada y apartidista, reclamó por la democratización de los medios y luchó en contra de la imposición de las representaciones mediáticas de los candidatos. Su organización y convocatoria se desarrollaron de manera particular, aunque no exclusiva, a través del uso de redes; sin embargo, su repertorio de acción se centró más en la ocupación del espacio público que en la creación de contenidos audiovisuales. En paralelo, el Partido Revolucionario Institucional como principal adversario de dicho movimiento, recurrió a estrategias tecnopolíticas para estimular el contagio y la viralidad de sus narrativas mediáticas, resultando vencedor en la disputa política, ya que finalmente la campaña del candidato de dicho partido impuso sus enmarcados mediáticos en los electores, logrando así obtener la mayoría de votos en la jornada electoral.

En paralelo, observamos que en el proceso electoral del 2018 se formaron distintas inteligencias colectivas que se movilizaron, principalmente, a través de redes sociodigitales centrándose en la creación de contenidos audiovisuales. Estas movilizaciones no se distinguieron como expresiones reivindicativas sino como movimientos sociales de posición que favorecieron a un frente político en particular, el partido Movimiento de Regeneración Nacional, el cuál formó parte 
de la contienda electoral por la presidencia de la república con el candidato Andrés Manuel López Obrador.

La viralidad y el contagio fortalecieron la campaña y el triunfo de dicho candidato, aunque de manera simultánea, también se vio favorecido por masas de internautas que polarizaron la opinión pública y desacreditaron las estrategias comunicativas de otros frentes. Las campañas de los demás candidatos también recurrieron a estrategias tecnopolíticas y, sin embargo, el montaje programático de sus recursos narrativos dejaba en evidencia la ausencia de un carácter orgánico, dificultando la viralidad, el contagio y la formación de inteligencias colectivas que se movilizaran por el cumplimiento de su objetivo político.

En nuestras observaciones de campo durante el segundo periodo electoral, detectamos que la ausencia de una movilización reivindicativa o expresión política alternativa afín a los movimientos sociales, posiblemente el resurgimiento del \#YoSoy132, no es evidencia suficiente para negar la existencia de la tecnopolítica durante el proceso electoral mexicano del 2018; es decir que la apropiación política de las redes tuvo una presencia no reivindicativa durante este periodo. Aunque la candidatura de Andrés Manuel López Obrador representó una figura anti sistémica, lo hizo desde un partido político y no desde la sociedad civil organizada. La tecnopolítica de este proceso electoral no se redujo a dicho candidato y su campaña sino que tuvo presencia en los diferentes frentes políticos que compitieron por la presidencia de la república mediante diversos recursos narrativos y estrategias comunicativas, lo cual muestra dos cosas: por un lado reafirma el argumento de que la tecnopolítica es policéntrica y por otro lado, contradice la idea de que es siempre apartidista.

En otras palabras, durante los procesos electorales del 2012 y 2018 en México, todas y todos los actores políticos involucrados desde todos los frentes ideológicos hicieron diferentes usos de las redes sociodigitales. Con mayor vehemencia la contienda electoral del 2018, en su conjunto, se definió como un fenómeno tecnopolítico, en el que la reivindicación ciudadana permaneció ausente y las movilizaciones políticas se distinguieron por facetas de posición al buscar favorecer a determinados frentes políticos mediante diferentes estrategias de apropiación tecnológica.

En nuestro trabajo de campo identificamos que las campañas de los diferentes candidatos no fueron formaciones aisladas; por el contrario, se constituyeron como ensamblajes tecnopolíticos que se asociaron en una misma ecología mediática. Los tres frentes políticos y las afinidades que representaron no son formas sólidas ni separadas entre sí, sino asociaciones de ensamblajes contenidas en un entorno complejo y con vínculos muy específicos, de 
los que conviene tomar consideración para entender la formación de grupos en la contienda electoral.

En suma, los procesos electorales mexicanos de 2012 y 2018 son una muestra útil para reflexionar sobre el fenómeno de la tecnopolítica, permiten entender el fenómeno más allá de las expresiones reivindicativas. Son un ejemplo válido para entender la tecnopolítica a partir de una gran diversidad de actores que tienen intereses y objetivos políticos diferenciados. Es también un espacio útil para rastrear la manera en que diversos actores entran en disputas por la intención de transformar o de conservar las estructuras políticas, mediante diversos repertorios que incluyen el uso estratégico de redes sociodigitales y la creación de contenidos audiovisuales, que les permiten actuar en una ecología mediática compleja.

\section{Discusión}

En esta investigación analizamos los usos de redes digitales en los procesos electorales del 2012 y 2018 en México, lo cual permitió evidenciar que los recursos narrativos y las estrategias comunicativas en los procesos electorales funcionan como instrumentos a partir de los cuales se configuran las experiencias tecnopolíticas, no solo en sentidos reivindicativos sino también con intenciones de reproducción y conservación de las estructuras de poder.

Destacamos que la emergencia de las redes sociodigitales complejiza la ecología mediática en los procesos electorales, ya que las audiencias pueden consumir materiales audiovisuales en distintas escalas de hegemonía informativa, en las que se despliegan distintos intereses. No hay una conexión directa entre la escala de hegemonía informativa y la búsqueda de autonomía o de enmarcado, puede tratarse de un material audiovisual producido desde un espacio poco hegemónico, pero que busque reforzar el enmarcado mediático de un grupo hegemónico o viceversa. Esta complejidad supone el desdibujamiento de binarismos aparentes pues, ni los actores políticos son puramente déspotas que suprimen siempre la libertad de los individuos, ni los ciudadanos son todo el tiempo una víctima que se reivindica para luchar por sus derechos.

Por este motivo, es importante recurrir a teorías de ensamblajes y de actor red (Latour, 2005) para poder analizar el uso de redes sociodigitales en un contexto político, apelando a una explicación compleja que comprenda la suma de actantes involucrados en los procesos de formación de grupos en disputa, que se desplazan por ontologías planas como entidades discretas sin ser enteramente lo uno ni lo otro, sino elementos controversiales mediante los cuales se forman agrupaciones y se despliegan asociaciones, dando lugar a procesos de ensamblado y desensamblado tecnopolítico. 
Es importante tener reserva en nombrar lo nuevo y poder diferenciarlo de lo viejo. Sin duda el uso de redes sociodigitales ha facilitado novedosos tipos de interacción social, principalmente, en la interactividad que se da alrededor de materiales informativos como los de campaña electoral, los cuales, son oficialmente distribuidos desde las plataformas de los candidatos o partidos. Si nos detenemos a analizar algunos señalamientos que exaltan lo novedoso, podemos observar que sobresalen conjeturas respecto a la capacidad de influenciar o modelar la opinión pública, crear discusiones, difundir contenidos, cambiar o manipular la percepción de las audiencias en relación con algún candidato o campaña electoral, pero ¿son realmente estas capacidades exclusivas de formas novedosas de comunicación como las redes sociodigitales? ¿Acaso la televisión y la radio no fueron en su momento capaces de influenciar, crear y difundir contenidos o de manipular la percepción de la gente? Los analistas constantemente buscan justificar esta supuesta novedad, resaltando la relación entre humanos y máquinas, obviando el hecho de que las personas han construido su experiencia política vinculada a expresiones automatizadas desde antes de la aparición de las redes sociodigitales.

Por nuestra parte, argumentamos que existen dos novedades visibles en la ecología mediática a partir del uso de redes sociodigitales: primero, lejos de promover una democratización mediática capaz de derribar la verticalidad hegemónica de los medios tradicionales, es importante reconocer que el viejo enmarcado persiste, la diferencia estriba en que ahora puede ser sometido a crítica, juicio y desmitificación en los mismos espacios de distribución audiovisual. Las críticas en torno a los contenidos mediáticos siempre han tenido presencia, la novedad es que ahora es in situ y que, además, se hace en forma de nuevos materiales audiovisuales. Las audiencias pueden responder con herramientas similares, en el mismo lugar y, de manera simultánea, la representación mediática se negocia, se termina de definir desde la retroalimentación de las audiencias, principalmente las remakers y prosumidoras.

Segundo, la intervención en la producción de materiales audiovisuales por parte de agrupaciones y actores ajenos a los grupos de poder que dictaban la agenda mediática es posible, sin la necesidad de recurrir a intermediaciones ni acuerdos con los propietarios de los medios de comunicación, ni los antiguos productores. No solo las grandes firmas de medios producen contenido en torno al proceso electoral o la política nacional en general, sino que cualquier persona, grupo o empresa pueden generar contenidos e introducirse en las dinámicas de tal ecología mediática.

Otra característica importante de nuestra propuesta es romper con un esquema de interpretación binario. De manera que estas dos dimensiones 
(actores políticos y sociedad civil organizada), deben ser tratadas como una tipificación ideal que permite operacionalizar dimensiones empíricas de la tecnopolítica, a partir de reconocer que existen diferentes apropiaciones de las redes sociodigitales dirigidas al cumplimiento de objetivos políticos diversos y, en la mayoría de las veces, opuestos. La tarea de los análisis de la tecnopolítica consiste entonces en desenmarañar la diversidad de actores y las formas complejas en que estos se ensamblan y se desensamblan, dando lugar a la formación y deformación de grupos, movilizaciones o campañas políticas con diferentes intereses y estrategias de acción comunicativa.

La tecnopolítica no se reduce a expresiones reivindicativas, también se da en función de la dominación hegemónica y la conservación de estructuras políticas. Se trata de un deseo de participar en la dirección del Estado, ya sea por motivos idealistas o egoístas. La tecnopolítica también tiene la intención de conservar, distribuir o transferir el poder, para ello recurre al uso estratégico de redes sociodigitales, así como otros canales de comunicación y herramientas tecnológicas.

\section{Conclusiones}

Proponemos un esquema interpretativo que parte de reconocer la existencia y continuidad del enmarcado mediático, mismo que ostenta la capacidad de dictar — de arriba hacia abajo - parte de la agenda temática en las redes sociodigitales. Este enmarcado tiene mayor peso e influencia sobre una dimensión de la interacción digital a la que denominamos conexión-desconexión. Este tipo de interacciones alude a internautas que se encuentran conectados a la red, pero que no tienen la capacidad para triangular la información que consumen, de manera que pueden consumir materiales audiovisuales ya sea en Facebook o en Twitter y en su interpretación priman las unidades mínimas de sentido.

Las interpretaciones de estos usuarios quedan enmarcadas y, a pesar de estar conectados a la red, su navegación no se distribuye por diferentes canales de información para ampliar su espectro interpretativo. Están conectados, consumen materiales audiovisuales que interpretan y en torno a los que interactúan, gracias a que tienen acceso a Internet, pero a la vez, están desconectados de la multiplicidad de aristas por las que viaja la información o de nodos en los que esta se anida y se discute con mayor precisión. Consideramos que mayormente son dos los factores que influyen en esta configuración: la propia influencia del enmarcado mediático y una precaria asociación con dimensiones simbólicas, culturales y educativas.

Una de las expresiones más visibles de esta conexión-desconexión es lo que hemos entendido como arcaísmo digital, tal noción alude a conductas violentas y primitivas, que aparecen cuando los internautas navegan en rutas 
robustas que se enmarcan en unidades mínimas de sentido, en donde no ejercen la capacidad de triangular la información que consumen ni tampoco pueden navegar a través de una conexión más profunda. Así, se disponen a defender de manera violenta un argumento, una interpretación o idea a la que se adscriben. Consideramos que estas formas son expresiones antagónicas a la inteligencia colectiva descrita por Toret (et al. 2013); denominamos a esta oposición como multitud o masa digital, la cual se forma en la acumulación de usuarios conectados-desconectados que se manifiestan a través de expresiones arcaicas digitales.

La inteligencia colectiva es solamente una dimensión de la tecnopolítica, como antagonismo existe también una masa digital que es producto de una conglomeración de usuarios mediáticamente enmarcados. Estos fomentan conductas arcaicas en redes sociodigitales, debido a que están desconectados de una multiplicidad de capas de información que les permitan ampliar sus interpretaciones, pero conectados a espacios reducidos de la red que limitan y atrofian la civilidad de sus interacciones. A diferencia de la inteligencia colectiva, la masa digital no tiene como propósito la formación de un sujeto social basado en la ética de la integración, por el contrario, replantea la aniquilación de la colectividad con base en el repudio y el desprestigio de la otredad, de sus interpretaciones, afinidades y posicionamientos políticos.

La masa digital es consecuencia del miedo y la desinformación, es un depredador que actúa por pánico e impulsos míticos e irracionales, su acción colectiva se reduce al linchamiento. Destruye la tolerancia, el diálogo, así como la capacidad para el entendimiento, los acuerdos y las empatías que hacen posible la acción colectiva transformadora, sustituyéndola por una acción de masa que destruye. Por este motivo, las redes sociodigitales no solo potencian formas de organización en beneficio de la democracia, sino que son también canales en donde se fomentan acciones de intolerancia y represión. No solo la autocomunicación se ve afectada por el enmarcado mediático de los algoritmos y los bots, también la formación de inteligencias colectivas es contrarrestada por masas digitales en donde intervienen troles, fake news y arcaísmos digitales. Todo esto en su conjunto debe ser entendido como parte del fenómeno de la tecnopolítica. La polarización es la característica menos cuestionable del dialogo político en redes.

Existen expresiones antagónicas de la tecnopolítica, en la que el control y el dominio político se expresan principalmente a través de los enmarcados mediáticos, que promueven la formación de masas digitales contrarias a las inteligencias colectivas. Es necesario distinguir expresiones tecnopolíticas de posición que favorecen a determinados frentes políticos. También debemos 
aludir a mecanismos de apropiación de redes sociodigitales por parte de actores establecidos en el sistema político y por parte de medios de comunicación tradicional, en particular cuando aspiran a conservar estructuras o condiciones políticas.

\section{Referencias bibliográficas}

ÁNGELES, E. (2020). Análisis de la correlación ciberespacio-política desde el realismo: El caso de las elecciones presidenciales mexicanas de 2006, 2012 y 2018. Revista Mexicana de Estudios Electorales, 4(24), 111-149. Recuperado de https://tinyurl.com/t4vjrk7z

BARANDIARAN, X.; CALLEJA-LÓPEZ, A.; MONTERDE, A.; ARAGON, P.; LINARES, J.; ROMERO, C. y PEREIRA, A. (2017). Decidim: redes políticas y tecnopolíticas para la democracia participativa. Recerca, revista de pensament i anàlisi, (21), 137-150. doi.org/10.6035/Recerca.2017.21.8

BENKLER, Y.; FARIS, R.; ROBERTS, H. y BOURASSA, N. (09 de julio de 2018). Understanding Media and Information Quality in an Age of Artificial Intelligence, Automation, Algorithms and Machine Learning. Medium. Recuperado de https://tinyurl.com/yxn945kd

BRown, A.J. (2020). "Should I Stay or Should I Leave?": Exploring (Dis) continued Facebook Use After the Cambridge Analytica Scandal. Social Media+ Society, 6(1), 1-8. doi.org/10.1177/2056305120913884

CADWALLADR, C. Y GRAHAM-HARRISON, E. (17 de marzo de 2018). Revealed: 50 million Facebook profiles harvested for Cambridge Analytica in major data breach. The Guardian. Recuperado de https://tiyurl.com/2smp95c5

CASTELLS, M. (2009). Comunicación y poder. Madrid: Alianza Editorial.

CASTELLS, M. (2012). Redes de indignación y esperanza. Los movimientos sociales en la era de internet. Madrid: Alianza Editorial.

CNN. [CNN en Español]. (11 de abril de 2018). México investiga posible injerencia de Cambridge Analytica en elecciones. [Archivo de Video]. CNN. Recuperado de https://tinyurl.com/ye3m2et6

EARLE, E. (2012). A brief history of occupy wallstreet. Rosa Luxemburg Stiftung, 2, pp. 1-20. Recuperado de https://tinyurl.com/2n8wjcu6

ESCOBAR, A. y OSTERWEIL, M. (2009). Movimientos sociales y la política de lo virtual. Estrategias Deleuzianas. Tabula rasa. (10), 123-161. Recuperado de https://tinyurl.com/xbjwfk74

FLORES-MÁRQUEZ, D. (2020). Estéticas activistas: cultura mediática y resonancia en las movilizaciones contemporáneas. Dígitos. Revista de Comunicación Digital, 6, 181-196. doi.org/10.7203/rd.v1i6.175 
García, M. y ChICAízA, L. (2018). Brexit, Paz y Trump: Enseñanzas Para Los Economistas. Revista de Economía Institucional, 20(38), 129-156. Recuperado de https: / / tinyurl.com/4n7rwkba

GONZALEZ-QUIJANO, Y. (2011). Las revueltas árabes en tiempo de transición digital. Mitos y realidades. Nueva sociedad, (235). Recuperado de https: / / tinyurl.com/3h3jz7u3

JAMIESON, K. y CAPPELLA, J. (2008). Echo chamber: Rush Limbaugh and the conservative media establishment. Oxford: Oxford University Press.

LATOUR, B. (2005). Reensamblar lo social. Una introducción a la teoría del actorred. Buenos Aires: Manantial.

LUHMANN, N. (1991). Sistemas sociales: Lineamientos para una teoría general. Distrito Federal: Universidad Iberoamericana y Alianza Editorial.

MARTínEZ, J. (21 de marzo de 2018). La compañía que burló la intimidad de 50 millones de estadounidenses. El País. Recuperado de https: / / tinyurl.com/3m99ncpu

MAtURANA, H. y VARELA, F. (1994). De máquinas y seres vivos. Santiago: Editorial Universitaria.

MonTERO, D. y CANDÓN, J. (2015). Sobre las imágenes del 15M. El videoactivismo como experimentación cultural y política. En: F. SIERRA, y D. MONTERo (eds.). Videoactivismo y movimientos sociales. Teoría y praxis de las multitudes conectadas. (pp. 832-457) Barcelona: Gedisa.

PARDO, P. (19 de julio de 2018). Donald Trump sabía de la injerencia rusa en las elecciones desde antes de tomar posesión como presidente. Internacional. El mundo. Recuperado de https: / /tinyurl.com/e2dpbea4

PInK, S.; HoRST, H.; POSTILl, J.; HJORTH, L.; LEWIS, T. y TACCHI, J. (2016). Digital Ethnography. Principles and Practice. London: Sage.

RAMíREZ, F.V. (2020). Juventud y movimientos sociales: reflexiones sobre la Generación Glocal latinoamericana. Revista Argentina de Estudios de Juventud. doi.org/10.24215/18524907e030

REGUILLO, R. (2015). La turbulencia en el paisaje: de jóvenes, necropolítica y 43 esperanzas. En J. VALENZUELA (eds.). Juvenicidio. Ayotzinapa y las vidas precarias en América Latina y España. (pp. 59-78). Barcelona: Ned Ediciones.

REguillo, R. (2017). Paisajes insurrectos. Jóvenes, redes y revueltas en el otoño civilizatorio. Barcelona: NED.

RIVERA VELÁZQUEZ, J. (18 de febrero de 2018), El convenio INE-Facebook. Excélsior. Excelsior. Recuperado de https://tinyurl.com/dtx966tm RoDríGUEZ, D. y TORRES, J. (2003). Autopoiesis, la unidad de una diferencia: Luhmann y Maturana. Sociologías. 5(9), 106-140. Recuperado de https://tinyurl.com/swxehakv 
RossenberG, M.; CONFesSORE, N. y CADWALLADR, C. (17 de marzo de 2018). How Trump Consultants Exploited the Facebook Data of Million. The New York Times. Recuperado de https://tinyurl.com/4hsxyty

TillY, C. (2010). Los movimientos sociales, 1768 - 2008. Desde sus orígenes a Facebook. Barcelona: Crítica.

ToRet, J.; CAlleja, A.; MARÍN, Ó.; ARAGón, P.; AGuilera, M. y Lumbreras, A. (2013). Tecnopolítica: la potencia de las multitudes conectadas. El sistema red 15M, un nuevo paradigma de la política distribuida. Barcelona: Universitat Oberta de Catalunya.

TORET, J. y PÉREZ, J. (2012). Devenir ciborg, era posmediática y maquinas tecnopolíticas Guattari en la sociedad red. En: B. GABRIELA (eds.). Félix Guattari. Los ecos del pensar. Entre la filosofía, el arte y la clínica. Valencia: Ediciones Letras Salvajes.

TRERÉ E. (2015). Ecología del videoactivismo contemporáneo en México: alcances y limitaciones de las prácticas de resistencia en las redes digitales. En F. SiERRA y D. MONTERo (eds.). Videoactivismo y movimientos sociales. Teoría y praxis de las multitudes conectadas. (pp. 167-187) Barcelona: Gedisa.

TRERÉ, E. (2016). Del levantamiento zapatista al escándalo NSA: Lecciones aprendidas, debates actuales y futuros desafíos de la resistencia digital. En J. CANDÓn y L. BENíTEZ (eds.). Activismo digital y nuevos modos de ciudadanía: Una mirada global. (pp. 40-59) Barcelona: InCom-UAB.

VALLE, I. (2015). \#YoSoy132: entre la estructura y la agencia, protocolos de resistencia. En: J. VALENZUELA (eds.). El sistema es antinosotros. Culturas, movimientos y resistencias juveniles. Tijuana: El Colegio de la Frontera norte.

VELÁSQUEZ LOALZA, M. (10 de noviembre de 2016). Trump, Brexit, Colombia... ¿Por qué se equivocan las encuestas? CNN. Recuperado de https://tinyurl.com/5z9snyzf

Ventura, A. (2018). Prefacio. En D., Gambetta [autor]. Politica, cultura algoritmica e conflitti al tempo dei big data. Génova: DEditore. 